\title{
Application of the synthetic wax to improve the foamed bitumen parameters used in half-warm bituminous mixtures
}

\author{
Marek Iwański, Anna Chomicz-Kowalska, Justyna Mrugała \\ Kielce University of Technology, Al. Tysiąclecia Państwa Polskiego 7, 25-314 Kielce, Poland
}

\begin{abstract}
The need for bitumen modification allowing lower asphalt production temperatures is a direct result of economic and environmental issues. Compared with the traditional Hot Mix Asphalt (HMA) technology, foamed bitumen used in the Warm and Half Warm Mix Asphalt (WMA, HWMA) processes provides an approximately $30-40{ }^{\circ} \mathrm{C}$ reduction in operating temperatures. This paper analyses the effect of the Fischer-Tropsch (FT) wax modifier on foamed bitumen parameters. The evaluation is focused on the basic properties of the binder and the parameters of the bituminous foam. The tests were performed on $35 / 50$ and 50/70 penetration grade binders for road construction, modified with $0.5 \%$ to $2.5 \%$ FT wax, added with an increment of $0.5 \%$ relative to the bitumen mass. The following basic parameters were evaluated (before the foaming process): penetration, Fraass breaking point and softening point. The bitumen foam parameters were measured at the foaming water content $(F W C)$ in the range from $1.5 \%$ to $4.0 \%$ with an increment of $0.5 \%$. The tests allowed determining optimal application ranges for the $F T$ and the $F W C$ to produce asphalt at lower temperatures.
\end{abstract}

Keywords: Fischer-Tropsch wax; foamed bitumen; foaming water content; expansion ratio; half-life.

\section{Introduction}

Today in Poland, the routinely used technology for producing bituminous mixtures for structural layers is HMA (Hot Mix Asphalt), in which aggregate and bitumen are heated to high temperatures exceeding $150{ }^{\circ} \mathrm{C}$. This method is not only energy-consuming but also contributes to high greenhouse gas emissions, which have a negative impact on natural environments.

The idea of reducing the levels of energy and harmful substances released to the atmosphere through the road construction has been debated for a long time now [1]. As early as 1956 Dr Ladis H. Csanyi, professor of the Iowa State University investigated possible production of bitumen in a form of foam during the cold production of bituminous mixtures CMA (Cold Mix Asphalt). In 1968, Mobil Oil Australia acquired the patent rights to Prof. Csanyi's invention and modified the process by replacing the steam with cold water. Since then this process has been widely used [2]. For the last ten years or more, a group of technologies, referred to as WMA (Warm Mix Asphalt), has been in common use. The temperatures at which WMA bituminous mixtures are produced range from $100{ }^{\circ} \mathrm{C}$ to $140{ }^{\circ} \mathrm{C}$. Lowering the temperature is only possible by adding chemicals (surfactants) of by reducing the viscosity of binders with use of organic modifiers such as Fischer-Tropsch (FT) synthetic wax. This type of wax affects bitumen rheological properties considerably, raising the viscosity of binders at temperatures below $100{ }^{\circ} \mathrm{C}$ and increasing their softening temperature. At temperatures exceeding $100{ }^{\circ} \mathrm{C}$, FT wax decreases the bitumen viscosity allowing the reduction in the mixture compaction temperature of approximately $30{ }^{\circ} \mathrm{C}$ [3].

The reduction in manufacturing and placing temperatures of bituminous mixtures is also possible through the modification of the process with use of foaming in the presence of water or zeolite. Jenkins et al. [4] developed a new bituminous mixture production method, half-warm process (HWMA) with foamed bitumen and temperatures below $100^{\circ} \mathrm{C}$. Compared with WMA, the foaming technology with water does not require any chemical additives [5] as long as the binder has the right foaming properties.

Mix production technologies that require lower temperatures contribute to the protection of natural environment by definite reduction in harmful emissions of hot asphalt technologies and lead to decreased use of energy necessary to produce bituminous mixtures [1], [5-7]. Researchers are still searching for new durable road materials and mixes [8], [9].

Corresponding author: Anna Chomicz-Kowalska. E-mail address: akowalska@tu.kielce.pl

http://dx.doi.org/10.3846/enviro.2014.154

(C) 2014 The Authors. Published by VGTU Press. This is an open-access article distributed under the terms of the Creative Commons Attribution License, which permits unrestricted use, distribution, and reproduction in any medium, provided the original author and source are credited. 
The introduction of HWMA with foamed bitumen is beneficial as they are able to solve many technological problems connected with environmental and economic considerations.

\section{Materials and research methodology}

\subsection{Tested materials}

Road construction employs many different types of bitumen whose physical and rheological properties are dependent on various factors including the type of crude petroleum from which they derive, refining process, chemical make-up and colloidal structure [10]. Jenkins [11] noted that the quality of the foam is affected by the following propertied of bitumen: viscosity versus temperature relationships, ratio of maltenes and asphaltenes, and bitumen composition. Each type of bitumen will thus behave differently when subjected to foaming. As the harder bitumen tends to clog the expansion chamber and the spray nozzle orifices, higher-grade bitumen is preferred, where clogging is practically eliminated [11]. Softer bitumen gives foams of better properties [11] but has a negative impact on providing bituminous mixtures with proper resistance to permanent deformation. Bissada [12] and Abel [13] also observed that soft grades of bitumen (with lower viscosities) have better foaming properties, higher expansion ratio and longer half-life $(H L)$ than the hard grades (with higher viscosities), which in turn ensure better dispersion and proper coating of the mineral material. Different behaviour in respect to decay parameters of two penetration grades $(P G)$ of bitumen (PG 60, PG 100) was reported by He and Wong [14]. Under the same test conditions (bitumen temperature, air pressure, and water content), higher values of expansion ratio $(E R)$ were obtained for harder binders. In addition, He and Wong observed a reverse relationship when analysing $H L$, which was longer for the softer bitumen (PG 100). They concluded that the major factor in the relationships they observed was the difference in viscosity between the binders.

Laboratory tests were carried out on road petroleum binders of 35/50 and 50/70 Pen grade, which are recommended for the production of hot bituminous mixes intended for pavement structural layers by Polish Technical Requirements WT-2 [15]. The bitumen was modified with the synthetic FT wax which by decreasing the binder viscosity at temperatures higher than $100 \mathrm{C}$ [3] (before foaming) improves the parameters of the bitumen foam, responsible for its proper dispersion and coating of the mineral material. As FT wax increases the binder stiffness, mechanical properties of MMA are better including higher resistance to permanent deformation [3], [7].

\subsection{Experimental program}

The aim of the laboratory tests was to establish the impact of the synthetic $F T$ wax on variability in properties of a $35 / 50$ Pen bitumen and a 50/70 Pen bitumen, and of based on them cold foamed bitumen intended for the use in the production of half-warm bituminous mixes. The modifier content in both binders was from $0.5 \%$ to $2.5 \%$ with an increment of $0.5 \%$ by mass. The samples were prepared to EN 12594 and tested before and after modification. The testing was divided into two stages. Basic parameters of the road bitumen before foaming were determined during the first stage of the tests. In the second stage, the qualities of the bitumen foam were measured.

\subsection{Bitumen properties}

Analysis of the influence of the synthetic wax in the range $0.5 \%$ to $2.5 \%$ on the properties of $35 / 50$ and $50 / 70$ Pen binders was conducted following the determination of:

- penetration grade $(P G)$ acc. to EN 1426;

- $\quad$ softening point temperature $\left(T_{R \& B}\right)$ acc. to EN 1427 ;

- breaking point temperature $\left(T_{\text {Fraass }}\right)$ acc. to EN 12593.

An additional parameter found during the tests was the penetration index $(P I)$, which helps evaluate the thermal sensitivity of the bitumen and indicates the dynamics of the bitumen hardness changes at different temperatures. The $P I$ is determined in accordance with EN 12591, based on the measurement of two basic rheological parameters of the bitumen $\left(T_{R \& B}, P G\right)$ following the formula:

$$
P I=\frac{20 T_{R \& B}+500 \log P G-1952}{T_{R \& B}-50 \log P G+120}
$$

\subsection{Foamed bitumen properties}

Physical properties of the bitumen foam are evaluated on the basis of two empirical parameters, expansion ratio (ER) and half-life $(H L)$ [11]. Expansion ratio is the ratio between maximum foam volume achieved and the volume of original bitumen (before foaming); it shows the volume increase during foaming, whereas the half-life is the time that the foam takes to collapse to half of its maximum volume, measured in seconds. The expansion ratio is a measure of the viscosity of the foam and provides an indication of how well the binder will disperse in the mineral mix to produce a uniform structure. The half-life is a measure of the stability of the foam and provides an indication of the speed of its collapse [11]. There is a 
reverse relationship between these two parameters, where increasing the content of foaming water causes an increase in the expansion ratio and decrease in the half-life [16].

The second stage of the tests involved determining parameters of the bitumen foam $(E R, H L)$ produced from the neat binders 35/50 and 50/70 Pen grade, and those modified with the FT wax. The characteristics were measured for the material manufactured under laboratory conditions with use of the lab-scale foamed bitumen plant WLB 10S by Wirtgen GmbH, widely employed for this purpose [17], [18], under the following conditions:

- temperature of bitumen (before foaming process) $155^{\circ} \mathrm{C}$;

- temperature of water $20{ }^{\circ} \mathrm{C}$;

- water flow $100 \mathrm{~g} / \mathrm{s}$;

- duration of foaming $5 \mathrm{~s}$;

- air pressure $500 \mathrm{kPa}$;

- water pressure $600 \mathrm{kPa}$.

The optimum characteristics of the bitumen foam were studied at the foaming water content ( $F W C$ ) from $1.5 \%$ to $4.0 \%$ added at a rate of $0.5 \%$ by mass. The results from testing the foaming parameters helped determine the levels of $F W C$ and FT wax content for HWMA.

The amounts of the foaming water used and the conditions of the foam production were selected based on the authors' own experience [19-20] and the experience of other researchers [5], [21-24].

\section{Results and discussion}

\subsection{Testing the effect of the FT wax content on basic bitumen properties}

In the first stage of testing, the basic rheological parameters were measured before and after modification, including penetration grade $(P G)$, softening point temperature $\left(T_{R \& B}\right)$, breaking point temperature $\left(T_{\text {Fraass }}\right)$ and penetration index $(P I)$. The overall aim of the tests was to determine the effect of the FT wax amount on the changes in the properties of $35 / 50$ and $50 / 70$ Pen binders. Figure 1 illustrates the mean values of the parameters together with the $95 \%$ confidence interval.

(a)

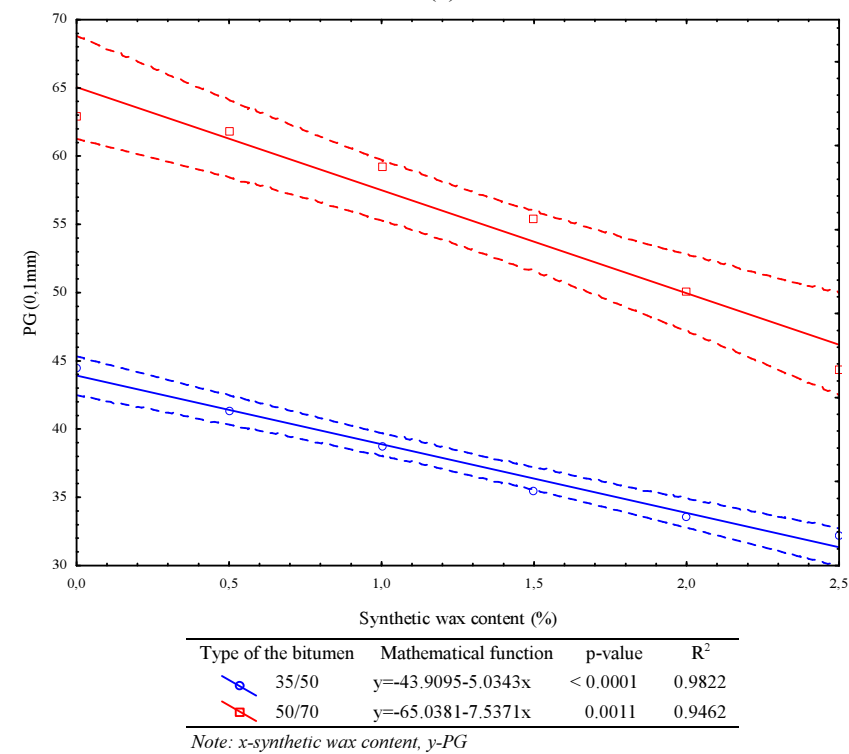

(c) (b)

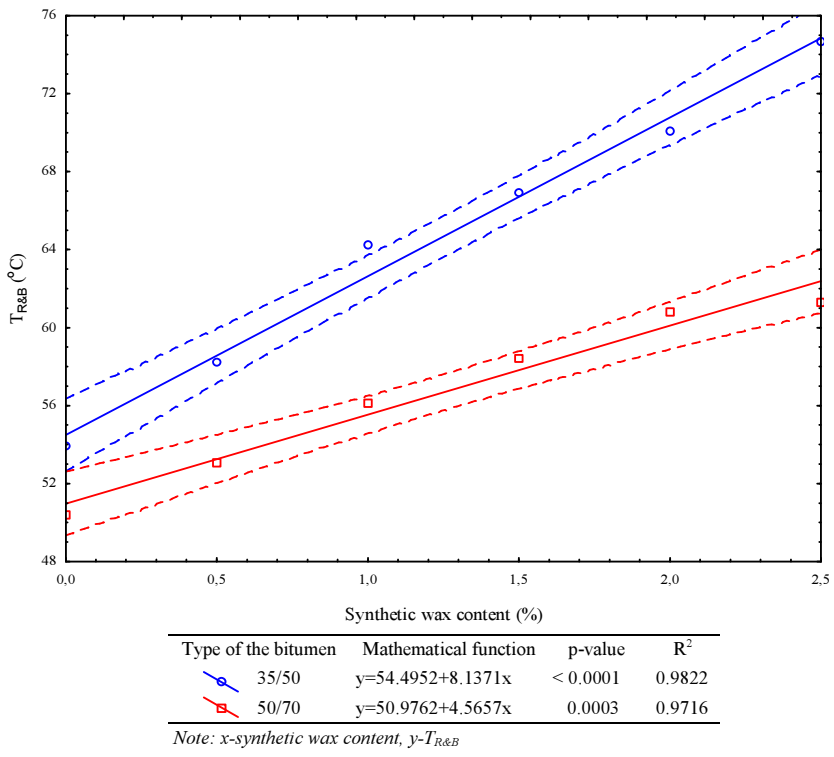

(d) 

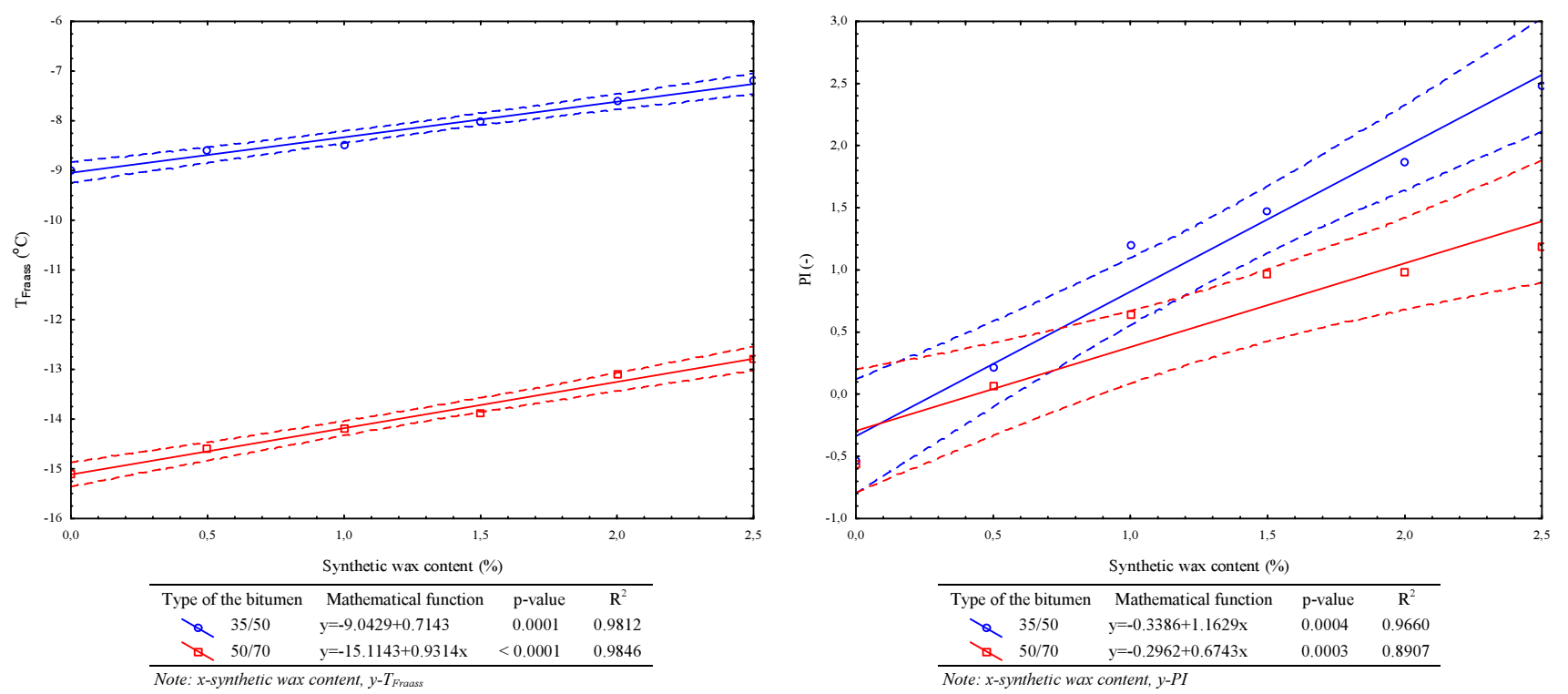

Fig. 1. Effect of the FT wax addition on changes in penetration grade (a), softening point temperature (b), breaking point temperature (c) and penetration index $(\mathrm{d})$

The relationships above indicate that an increase in the content of the $F T$ modifier causes significant changes in the characteristics of binders under investigation.

The penetration value decreased with increasing content of the FT wax in the range from $0.5 \%$ to $2.5 \%$, which made the binder harder. The lesser effect was observed for the $35 / 50$ Pen binders, where the value of $P G$ decreased by approximately $12[0.1 \mathrm{~mm}]$ relative to more than $18[0.1 \mathrm{~mm}]$ for the $50 / 70$ Pen binders.

From fig. $1 \mathrm{~b}$ it follows that the softening temperature increased with the increasing amount of modifier for both binders. Higher increase (before and after modification) was noted for the $35 / 50$ Pen binder (of $20.8^{\circ} \mathrm{C}$ ), with a two times smaller increase recorded for the 50/70 Pen binder (of $10.9^{\circ} \mathrm{C}$ ). With reference to a temperature of $60{ }^{\circ} \mathrm{C}$ considered the maximum pavement temperature in summer and taken into account in evaluations of the resistance to permanent deformation (rutting test to WT-2 2010 [15] and EN 12697-22), the softening temperature level higher than that was achieved for the 35/50 Pen binder with the $F T$ was content above $0.75 \%$, whereas for the $50 / 70$ Pen binder this level was not less than $2.0 \%$. It can be thus concluded that the rise in the softening temperature obtained through modification will limit the susceptibility of both mixes to permanent deformations [3], [7].

The breaking point temperature test results lead to the conclusion that modification of the two binders (35/50 and 50/70) did not cause any significant differences in the rate of changes (Fig. 1c). Increased concentration of FT wax in both binders had an influence on the increase in the breaking point temperature, which means that the bitumen became more brittle at low temperatures. The breaking point temperature increased from $-9{ }^{\circ} \mathrm{C}$ to $-7.2{ }^{\circ} \mathrm{C}$ for the $35 / 50$ Pen bitumen and from $-15.1{ }^{\circ} \mathrm{C}$ to $12.8^{\circ} \mathrm{C}$ for the $50 / 70$ Pen bitumen.

The penetration index was the last parameter to be evaluated in the preliminary classification of binders according to their viscoelastic state. The penetration index values rose with increasing amount of the $F T$ wax in the binders. The highest PI increase dynamics was recorded for both binders when the modifier content increased up to $1.0 \%$. Further increase in its concentration resulted in less influence on the $P I$ changes in binders $35 / 50$ and 50/70 penetration grades (before modification). Binders with $P I>+2.0$ are the gel-type binders which are less sensitive to temperature but are very brittle at lower temperatures [10]. The 35/50 Pen grade bitumen with the maximum FT wax concentration achieved the apparent limit beyond which binders become gels. Application of 2.5\% modifier to the 35/50 Pen grade bitumen reduces the thermal susceptibility of the binder but its increased stiffness can affect the rise in bitumen brittleness at low temperature [25].

The $p$-values for the F statistic, smaller $(p$-value $<0.0001)$ than the assumed confidence level $(\alpha=0.05)$ indicated that the amount of the $F T$ wax had a significant effect on the magnitude of all the parameters in question $\left(P G, T_{R \& B}, T_{\text {Fraass }}, P I\right)$.

\subsection{Investigating the effect of the FT wax content on foamed bitumen properties}

The basic criterion for the evaluation of binder suitability for foaming is its ability to produce the foam that shows required parameters. The knowledge of the basic rheological characteristics of bitumen is insufficient to be able to estimate its foaming levels. Therefore the measurement of the bitumen foam parameters was carried out on the neat binders $(35 / 50$ and $50 / 70)$ and on the binders modified with $F T$ wax $(0.5 \%, 1.0 \%, 1.5 \%, 2.0 \%, 2.5 \%)$.

As mentioned earlier, the second stage of the testing involved analysing two bitumen foam parameters, expansion ratio $(E R)$ and half-life $(H L)$. To properly evaluate the properties of the foam, the parameters were measured four times with varied amount of $F W C(1.5 \%, 2.0 \%, 2.5 \%, 3.0 \%, 3.5 \%, 4.0 \%)$. 
In the first stage of the investigation, the results obtained helped develop relationships (Fig. 3) between the parameters $(E R, H L)$ and the change in the level of the water added during foaming. The resulting characteristics were the basis for determining the optimum foaming water content for each binder type. Figure 2 shows mean values of the characteristics for both neat binders (non-modified) and the graphical method of determining optimum $F W C$ recommended by Kim and Lee [26]. Table 1 summarises mean $E R$ and $H L$ values obtained in that way at the optimum $F W C$ for the modified binders.

To evaluate the influence of changes in $F W C$ and $F T$ wax content on the properties of the bitumen binders, a model in a form of a second degree polynomial was chosen, described with the following equation

$$
y=b_{0}+b_{1} \cdot x_{1}+b_{2} \cdot x_{2}+b_{3} \cdot x_{2} \cdot x_{1}+b_{4} \cdot x_{1}^{2}+b_{5} \cdot x_{2}^{2},
$$

where: $x_{1}-$ foaming water content $(\%)$;

$x_{2}-F T$ wax content $(\%)$;

$b_{0}-b_{5}-$ values of experimental coefficients.

Figure 4 shows the graphical interpretation of the response surface for the expansion ratio and the half-life in relation to the amount of the synthetic wax and foaming water contents.

(a)

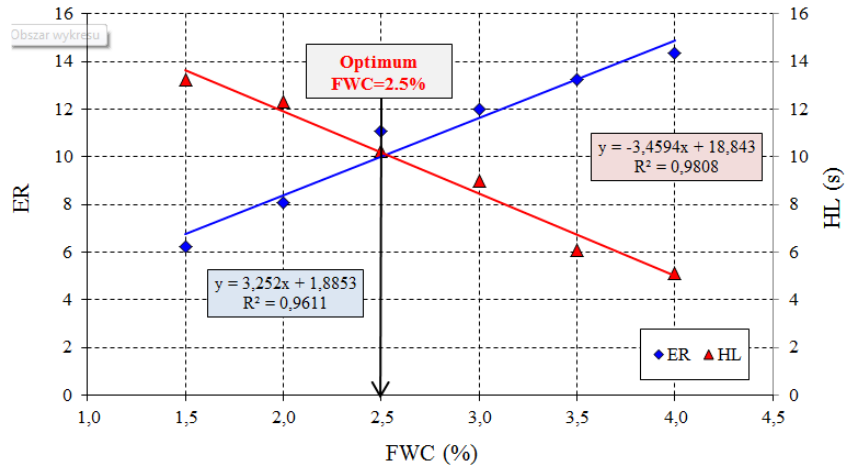

(b)

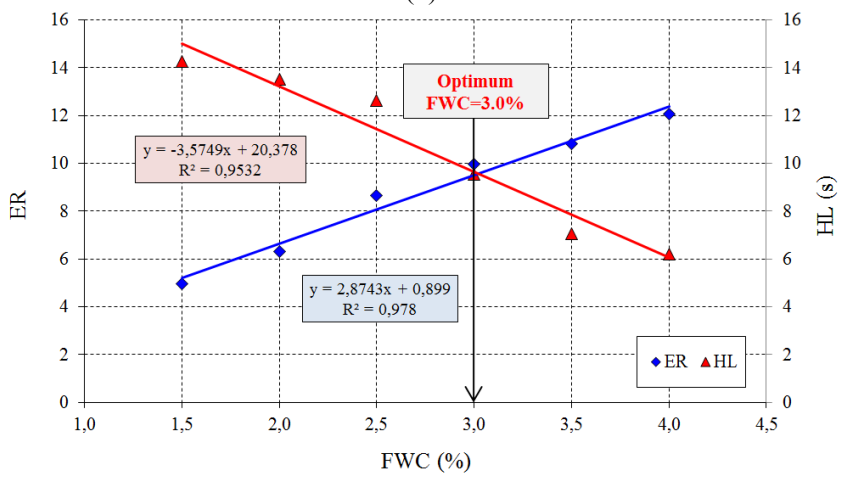

Fig. 2. Determining the optimum $F W C$ for bitumen $35 / 50$ (a) and 50/70 (b)

(a)

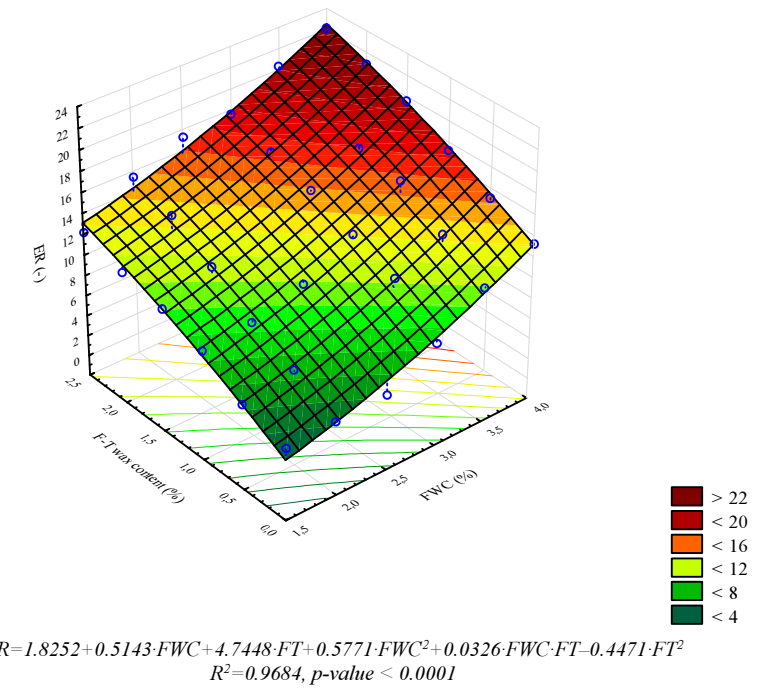

(c) (b)

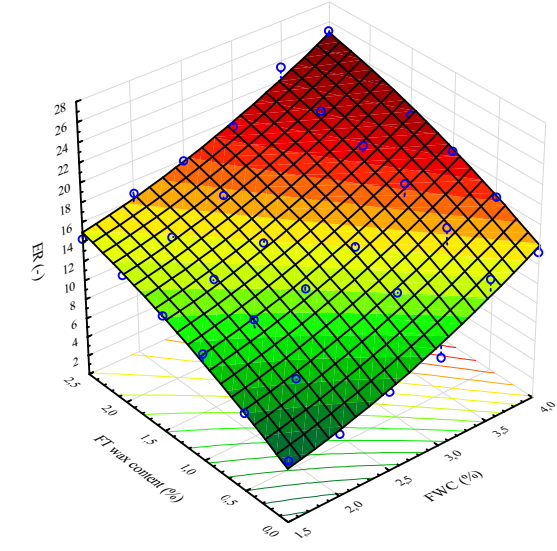

$E R=3.7542+0.0543 \cdot F W C+5.376 \cdot F T+0.7449 \cdot F W C^{2}-0.0708 \cdot F W C \cdot F T-0.5973 \cdot F T^{2}$ $R^{2}=0.9427$, p-value $<0.0001$

(d) 


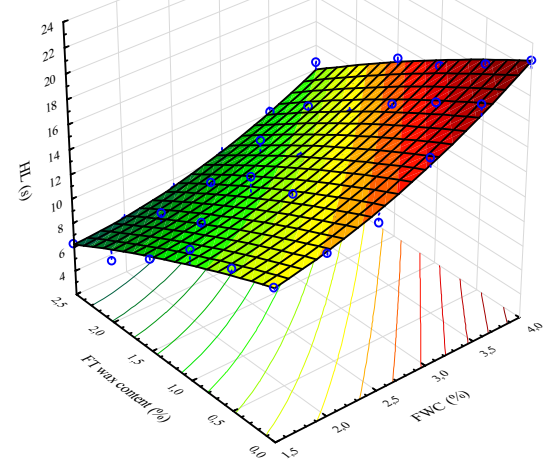

$H L=13.908-0.91 \cdot F W C-1.9992 \cdot F T+0.7757 \cdot F W C^{2}-0.4237 \cdot F W C \cdot F T-0.2354 \cdot F T^{2}$ $R^{2}=0.9573$, p-value $<0.0001$

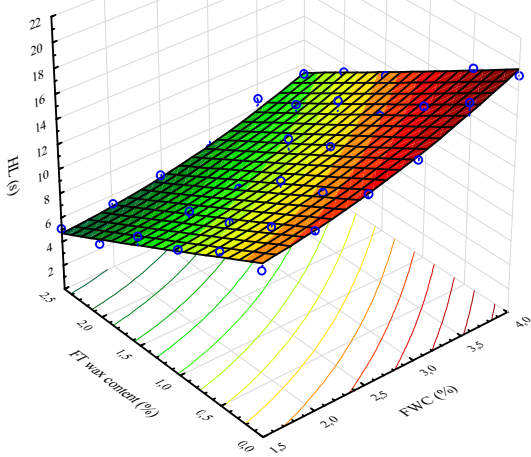

$H L=13.543-0.6479 \cdot F W C-3.4261 \cdot F T+0.5415 \cdot F W C^{2}-0.2006 \cdot F W C \cdot F T+0.0355 \cdot F T^{2}$ $R^{2}=0.9378, p$-value $<0.0001$

Fig. 4. Impact of the change in the levels of $F T$ wax content and $F W C$ on the parameters $(E R, H L)$ of the foam produced from binders $35 / 50(a-b)$ and $50 / 70(c-d)$

(a)

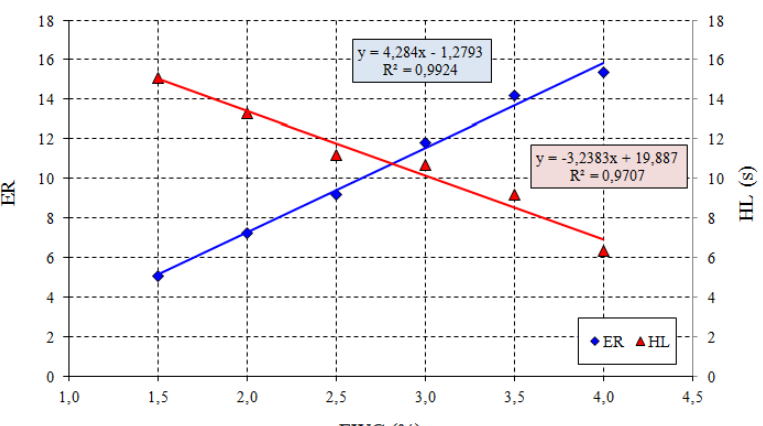

(b)

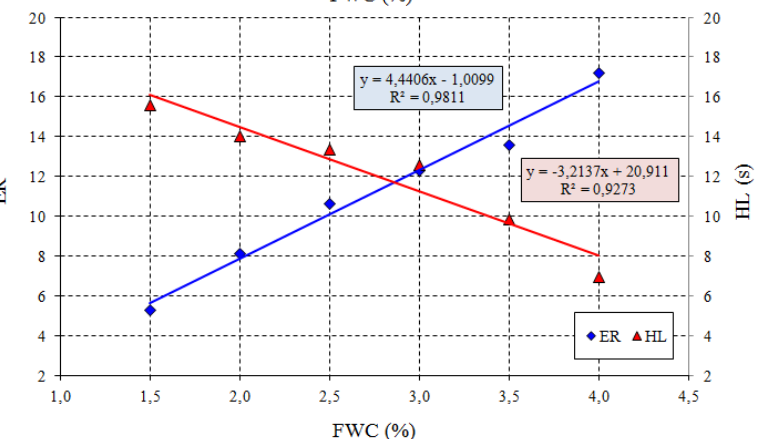

(c)

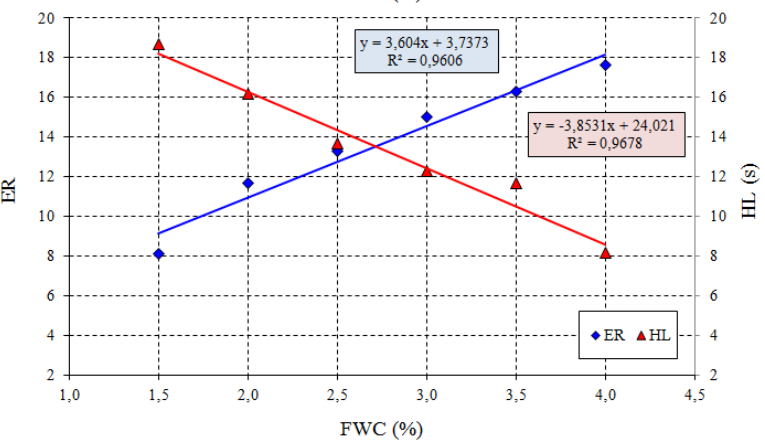

(f)

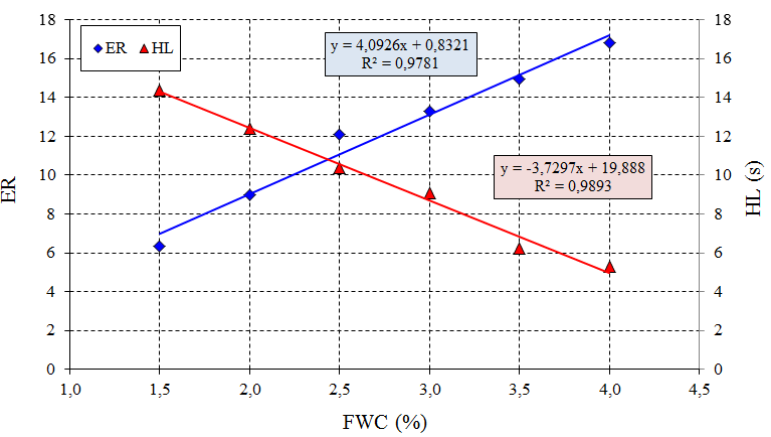

(g)

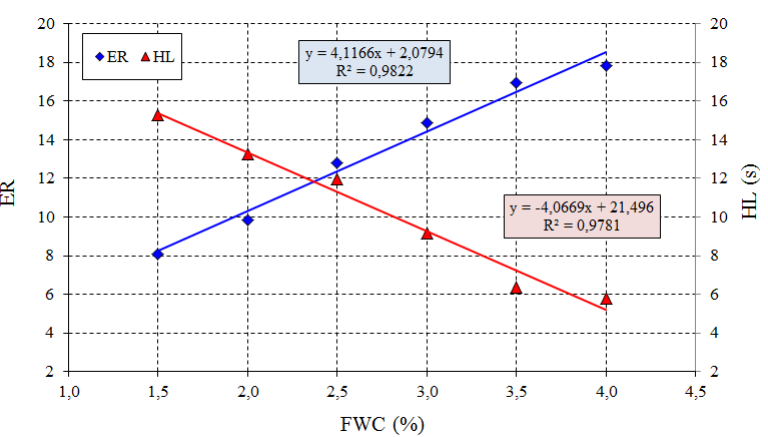

(h)

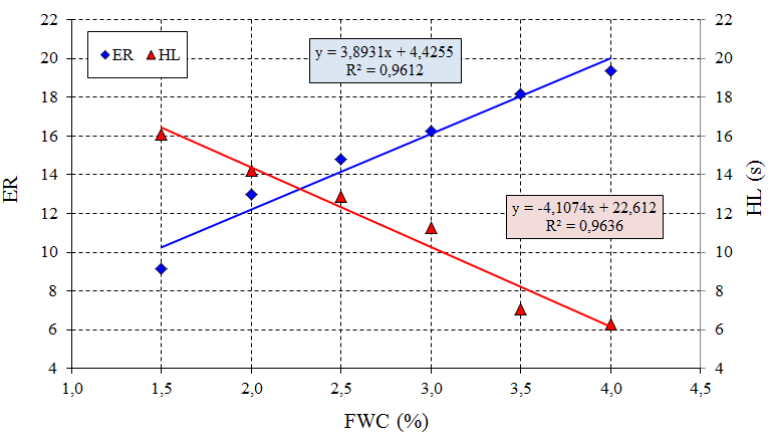


(d)

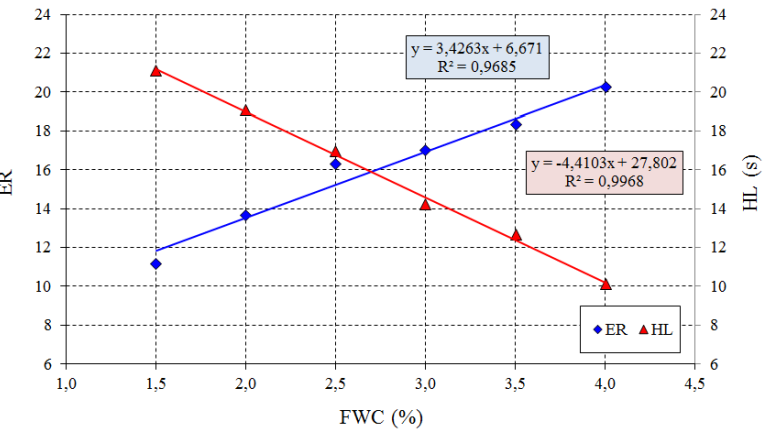

(e)

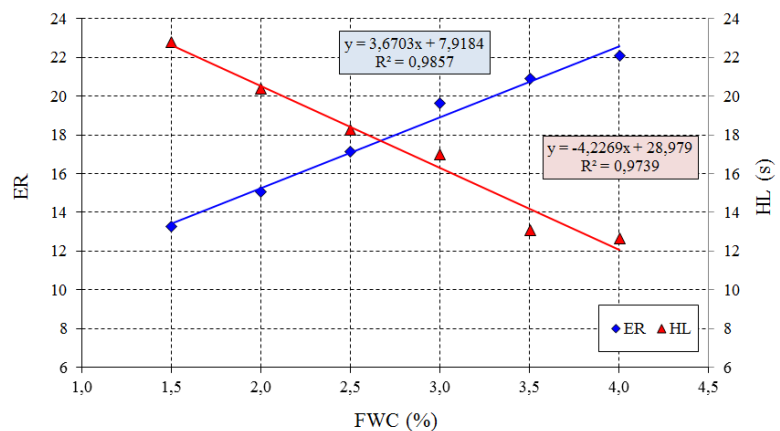

(i)

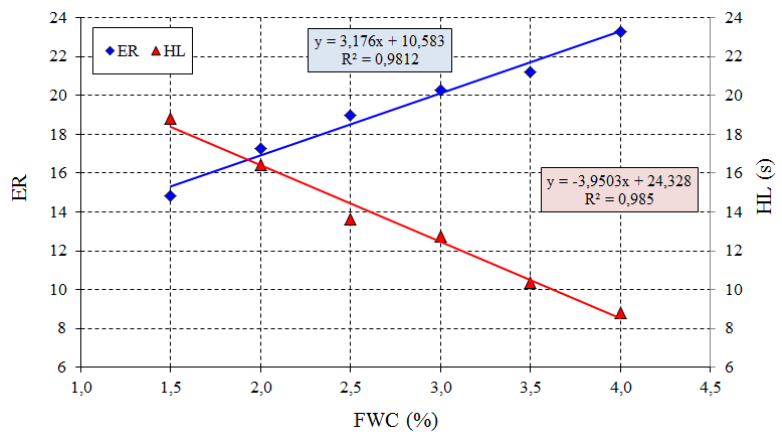

(j)

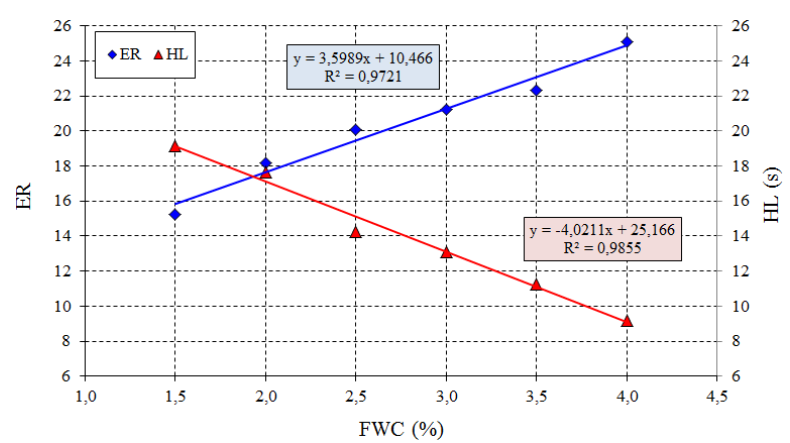

Fig. 3. Parameters of foamed bitumen produced from binders $35 / 50(\mathrm{a}-\mathrm{e})$ and $50 / 70(\mathrm{f}-\mathrm{j})$ modified with $F T$ wax in the amounts of $0.5 \%(\mathrm{a}, \mathrm{f}), 1.0 \%(\mathrm{~b}, \mathrm{~g})$, $1.5 \%(\mathrm{c}, \mathrm{h}), 2.0 \%(\mathrm{~d}, \mathrm{i})$, and $2.5 \%(\mathrm{e}, \mathrm{j})$

Table 1. Properties of foamed bitumen at optimum FWC

\begin{tabular}{lllll}
\hline $\begin{array}{l}\text { Type of } \\
\text { the bitumen }\end{array}$ & $\begin{array}{l}F T \text { wax } \\
\text { content (\%) }\end{array}$ & $E R$ & $\begin{array}{l}H L \\
(\mathrm{~s})\end{array}$ & $\begin{array}{l}\text { Optimum } \\
F W C(\%)\end{array}$ \\
\hline \multirow{5}{*}{$35 / 50$} & 0.0 & 9.98 & 9.55 & 3.0 \\
& 0.5 & 11.84 & 10.68 & 3.0 \\
& 1.0 & 12.34 & 12.57 & 3.0 \\
& 1.5 & 13.28 & 13.66 & 2.5 \\
& 2.0 & 16.27 & 16.94 & 2.5 \\
& 2.5 & 16.82 & 18.27 & 2.5 \\
\hline \multirow{3}{*}{$50 / 70$} & 0.0 & 11.06 & 10.23 & 2.5 \\
& 0.5 & 12.08 & 10.38 & 2.5 \\
& 1.0 & 12.78 & 11.98 & 2.5 \\
& 1.5 & 14.82 & 12.87 & 2.5 \\
& 2.0 & 17.26 & 16.42 & 2.0 \\
\hline
\end{tabular}

The regression models obtained (Fig 4) lead to the statement that increasing the water content during the foaming process had a definite effect on the parameters of the binders through increasing the values of their expansion ratios and half-lives. The values of coefficients of determination $\mathrm{R}^{2}$ obtained from the analysis indicate a good fit of the mathematical models to the data $\left(\mathrm{R}^{2}>0.92\right)$. The $p$-value for the $\mathrm{F}$ statistic obtained from the tests for $F T$ and $F W C$ is definitely smaller ( $p$-value $<$ $0.0001)$ than the assumed level of confidence $(\alpha=0.05)$, which means that the parameters in question have a significant effect on the changes in characteristics of the foamed bitumens studied.

A linear function (Figs 2, 3) was used to describe the relationships between the measured foaming parameters $(E R, H L)$ of the binders and the amount of water added during the foaming process. The coefficient of determination for the relationships recorded was $\mathrm{R}^{2}>0.93$ indicating that the proposed functions explain the test results variability to the degree greater than $93 \%$.

Determined in accordance to the recommendations of Muthen [2] optimum contents of water added during the foaming process, on the basis of the intersection of the expansion and the half-life curves, ensuring the bitumen foam stability vary according to the type of neat bitumen subjected to modification. A beneficial influence of the modification was recorded for both binders $(35 / 50,50 / 70)$ modified with $F T$ wax, where the expansion ratio and the half-life values increased due to the wax increased content (from $0.5 \%$ to $2.5 \%$ ). For the harder bitumen $(35 / 50$ ), the optimum $F W C$ was $3.0 \%$ with $F T$ wax concentrations from $0.0 \%$ to $1.0 \%$ and $F W C=2.5 \%$ and the modifier range $1.5 \%-2.5 \%$. For the softer binder $(50 / 70)$ the optimum contents of foaming water were lower. The major factors in this situation are the type of the original bitumen and 
the amount of wax, where the binder viscosity at temperatures above $100^{\circ} \mathrm{C}$ (before foaming) decreases with the increase in the FT wax content [3]. These results lead to the conclusion, also made by other researchers [12-13], that softer binders (with lower viscosity) show better foaming characteristics and allow reducing the amount of water used for foaming.

According to the guidance proposed by the Wirtgen Cold Recycling Technology [27] and the Technical Guideline 2 TG2 [28], the minimum allowable values of $E R$ and $H L$ should be 8 and 6 seconds, respectively. In contrast, Muthen [2] suggests minimum values of 10 and 12 seconds and the South African guidelines [29] recommend 7 seconds for both $E R$ and $H L$. The recommendations mentioned above relate to the cold mix recycling. Jenkins [11] developed the following recommendations for the minimum values of the foam parameters, relative to its intended use:

- $\quad$ surface dressing $E R=10, H L=30$ seconds;

- cold mixes $E R=15, H L=15$ seconds;

- RAP and half-warm mixes $E R=17, H L=13$ seconds;

- cold mixes containing materials with encapsulated contaminates e.g. tars) $E R=25, H L=10$ seconds.

According to the recommendations [11], half-warm mixes should be produced with bitumen of the following parameters: $E R \geq 17$ and $H L \geq 13$ seconds. This was the basis for selecting binders, intended for HWMA, which obtained the recommended values of $E R$ and $H L$ at the established levels of both factors $(F T, F W C)$ :

- for the 35/50 Pen binder: $F T=2.5 \%, F W C=2.5 \%, E R=17.15, H L=18.27 \mathrm{~s}$;

- for the 50/70 Pen binder: $F T=2.0 \%, F W C=2.0 \%, E R=17.26, H L=16.42$;

- for the 50/70 Pen binder: $F T=2.5 \%, F W C=2.0 \%, E R=18.17, H L=17.68 \mathrm{~s}$.

\section{Conclusion}

Analysis of the results from basic rheological tests carried out on neat binders (35/50 and 50/70) and on the binders modified with the synthetic wax, together with evaluation of the parameters of the foam led to the following conclusions:

- an increase in the synthetic wax content caused significant changes in the values of the basic binder characteristics and bitumen foam parameters;

- an increasing content of the FT wax (from $0.5 \%$ to $2.5 \%$ ) decreased the penetration value, and the softening temperature increased for both bitumens. As a result, the binder becoming harder will reduce the susceptibility of the bituminous mixtures to permanent deformations;

- modification of both types of binders (35/50 and 50/70) did not cause any significant differences in the rates of breaking point temperature change; its rise of approximately $2{ }^{\circ} \mathrm{C}$ was recorded;

- an influence of the synthetic wax content on the $P G$ level was weaker in the case of the 35/50 Pen binder compared with the 50/70 Pen binder, for which softening temperature increase was nearly half the magnitude of that for the binder before and after modification;

- an increase in the FT wax content in the binders investigated here improved their foaming power;

- an increase in the wax amount lead to an increase in the values of expansion ratios and half-lives of the foamed bitumens;

- very soft bitumens (50/70), regardless of the wax amount used, had better foaming parameters: higher expansion and longer half-life compared with the $35 / 50$ Pen binder;

- foamed bitumens derived from the $35 / 50$ Pen binder, with the maximum content of the synthetic wax $(F T=2.5 \%)$, and those from the 50/70 Pen binder with $2.0 \%$ and $2.5 \%$ wax contents at $F W C=2.5 \%$ achieved values higher than the recommended minimum values of $E R$ and $H L$, which confirms their suitability for use in manufacturing half-warm bituminous mixtures.

\section{Acknowledgements}

The scientific research has been carried out as o part of the Project "Innovative recourses and effective methods of safety improvement and durability of buildings and transport infrastructure in the sustainable development" (No POIG 01.01.0210-106/09-01) financed by the European Union from the European Fund of Regional Development based on the Operational Program of the Innovative Economy.

\section{References}

[1] Vaitkus, A.; Cygas, D. 2009. Analysis and evaluation of possibilities for the use of warm mix asphalt in Lithuania, The Baltic Journal of Road and Bridge Engineering 4(2): 80-86. http://dx.doi.org/10.3846/1822-427X.2009.4.80-86

[2] Muthen, K. M. 1999. Foamed asphalt mixes. Mix design procedure. Contract Report CR 98/077, SABITA Ltd \& CSIR Transportek (Council for Scientific and Industrial Research Transportek), Pretoria, South Africa. Available from Internet: http://asphalt.csir.co.za/FArefs/Muthen\%20$\% 20$ Mix\%20Design.pdf.

[3] Iwański, M.; Mazurek, G. 2013. Optimization of the Synthetic Wax Content on Example of Bitumen 35/50, Procedia Engineering 57: 414-423 http://dx.doi.org/10.1016/j.proeng.2013.04.054

[4] Jenkins, KJ.; de Groot, J. L. A.; Van de Ven, M. F. C.; Molenaar, A. A. A. 199. Half-warm Foamed Bitumen Treatment, in New Process. Conference on Asphalt pavements for Southern Africa, Victoria Falls, Zimbabwe. 
[5] Yu, X.; Wang. Y.; Luo, Y. 2013. Impacts of water content on rheological properties and performance-related behaviours of foamed war-mix asphalt, Construction and Building Materials 48: 203-209. http://dx.doi.org/10.1016/j.conbuildmat.2013.06.018

[6] Van De Ven, M. F. C.; Jenkins, K. J.; Voskuilen, J. L. M.; Van Den Beemt, R. 2007. Development of (half-) warm foamed bitumen mixes: State of the art, International Journal of Pavement Engineering 8(2): 163-175. Taylor and Francis. http://dx.doi.org/10.1080/10298430601149635

[7] Hugo, M. R. D.; Silva; Joel, R. M. Oliveira; Peralta, J. A.; Salah, E.; Zoorob, B. 2010. Optimization of warm mix asphalt using different blends of binders and synthetic paraffin wax contents, Construction and Building Materials 24(9): 1621-1631. http://dx.doi.org/10.1016/j.conbuildmat.2010.02.030

[8] Radziszewski, P. 2007. Modifed asphalt mixtures resistance to permanent deformation, Journal of Civil Engineering and Management 13(4): 307-315. Taylor and Francis. DOI: 10.1080/13923730.2007.9636451.

[9] Čygas, D.; Laurinavičius, A.; Vaitkus, A.; Perveneckas, Z.; Motiejūnas, A. 2008. Research of Asphalt Pavement Structures on Lithuanian Roads (I)., The Baltic Journal of Road and Bridge Engineering 3(2): 77-83. http://dx.doi.org/10.3846/1822-427X.2008.3.77-83

[10] Gaweł, I.; Kalabińska, M.; Piłat, J. 2001. Asfalty drogowe [Road bitumen]. WKŁ, Warszawa, Poland, 255 p.

[11] Jenkins, K. J. 2000. Mix Design Considerations for Cold and Half-Warm Bituminous Mixes with Emphasis on Foamed Bitumen. PhD Dissertation, Department of Civil Engineering, Faculty of Engineering, University of Stellenbosch, Stellenbosch, South Africa.

[12] Bissada, A. F. 1987. Structural Response of Foamed-Asphalt-Sand Mixtures in Hot Environments. In: Asphalt materials and mixtures. Washington, Transportation Research Record 1115: 134-149. Available from Internet: http://asphalt.csir.co.za/FArefs/Bissada.pdf.

[13] Abel, F. 1978. Foamed asphalt base stabilization. 6th Annual Asphalt Paving Seminar, Colorado State University.

[14] He, G.; Wong, W. 2006. Decay properties of foamed bitumens, Construction and Building Materials 20: 866-877, Elsevier, http://dx.doi.org/10.1016/j.conbuildmat.2005.06.027

[15] WT-2 2010. Wymagania Techniczne [Polish Technical Guideline]. Nawierzchnie asfaltowe na drogach krajowych [Asphal pavements on the national roads]. Załącznik $\mathrm{Nr} 2$ [Appendix 2], Warszawa, $48 \mathrm{p}$.

[16] Jenkins, K. J.; Molenaar, A. A. A.; de Groot, J. L. A.; Van de Ven, M. F. C. 2000. Optimisation and Application of Foamed Bitumen in Road Building. Wegbouwkundige Werkdagen, Doorwerth, Netherlands.

[17] Kim, Y.; Lee, H. D.; Heitzman, M. 2009. Dynamic Modulus and Repeated Load Tests of Cold In-Place Recycling Mixtures Using Foamed Asphalt, Journal of Materials in Civil Engineering 21(6): 279-285. http://dx.doi.org/10.1061/(ASCE)0899-1561(2009)21:6(279)

[18] Saleh, M. F. 2007. Cost evaluation of foam bitumen and other stabilization alternatives, International Journal of Pavement Engineering 8(2): 157-161. Taylor and Francis. http://dx.doi.org/10.1080/10298430601149585

[19] Iwański, M.; Chomicz-Kowalska, A. 2012. Moisture and frost resistance of the recycled base rehabilitated with the foamed bitumen technology, Archives of Civil Engineering, ISSN 1230-2945, Komitet Inżynierii Ląowej i Wodnej PAN, Vol. 58, nr 2, 2012, 185-198. Available from Internet: http://versita.metapress.com/content/h304561t24457521/fulltext.pdf. http://dx.doi.org/10.2478/v.10169-012-0011-2

[20] Iwański, M.; Chomicz-Kowalska, A. 2013. Laboratory Study on mechanical Parameters of Foamed Bitumen Mixtures in the Cold Recycling Technology, Procedia Engineering 57: 433-442, Elsevier. http://dx.doi.org/10.1016/j.proeng.2013.04.056

[21] Middleton, B.; Forflylow, RW. 2009. Evauation of warm-mix asphalt produced with the double barrel green process, Journal Transport Reserch Record 2126: 19-26. http://dx.doi.org/10.3141/2126-03

[22] Xiao, F.; Punith, V. S.; Putman, B.; Amirkhanin, S. 2011. Utilization of foaming technology in warm-mix asphalt mixtures containing moist aggregates, Journal Materials and Civil Engineering 23(9): 1328-1337. http://dx.doi.org/10.1061/(ASCE)MT.1943-5533.0000297

[23] Button, J. W.; Estakhri, C.; Wunsatt, A. 2007. A Synthesis of warm-mix asphalt. Report No. SWUTC/07/0-5597-1. Texas Transportation Institute, College Station, Texas.

[24] Fu, P.; Harvey, J. T.; Jones, D.; Chao, Y. C. 2008. Understanding internal structure characteristics of foamed asphalt mixes with fracture face image analyses, Transport Research Record 2057: 20-27. http://dx. doi.org/10.3141/2057-03

[25] Lu, X.; Langton, M.; Redelius, P. 2005. Wax morphology in bitumen, Journal of Materials Science 40: $1893-1900$.

[26] Kim, Y; Lee, D.Y. 2003. Development of a mix design process for cold-in place rehabilitation using foamed asphalt. Final report for TR-474 Phase 1, University of Iowa, USA.

[27] Wirtgen. 2012. Wirtgen Cold Recycling Technology [online], Wirtgen GmbH, Windhagen: Germany. Available from Internet: http://www.wirtgen.de/media/redaktion/pdf-dokumente/03_kaltrecycling_stabilisierung/_allgemein_1/manual/p_manual_e.pdf.

[28] Asphalt Academy. 2009. Technical Guideline: Bitumen Stabilised Materials, A Guideline for the Design and Construction of Bitumen Emulsion and Foamed Bitumen Stabilised Materials, Technical Gudeline 2 (TG2) [online]. Available from Internet: http://www.asphaltacademy.co.za/Documents/TG2May09.pdf.

[29] Asphalt Academy. 2002. Interim Technical Guidelines (TG2): The Design and Use of Foamed Bitumen Treated Materials [online]. CSIR, Pretoria, South Africa. 